\title{
Cultural Sensitivity Associated with Domestic Travel Study Program: Long-Term Impact
}

\author{
Jessica R. Eosso1, Marie Fanelli Kuczmarski', Ryan T. Pohlig2, Laura M. Lessard1, \\ Sandra D. Baker ${ }^{1}$
}

${ }^{1}$ Department of Behavioral Health and Nutrition, University of Delaware, Newark, USA

${ }^{2}$ College of Health Sciences, University of Delaware, Newark, USA

Email: jeosso@udel.edu

How to cite this paper: Eosso, J. R., Kuczmarski, M. F., Pohlig, R. T., Lessard, L. M., \& Baker, S. D. (2019). Cultural Sensitivity Associated with Domestic Travel Study Program: Long-Term Impact. Creative Education, 10, 111-127.

https://doi.org/10.4236/ce.2019.101008

Received: December 20, 2018

Accepted: January 13, 2019

Published: January 16, 2019

Copyright $\odot 2019$ by author(s) and Scientific Research Publishing Inc. This work is licensed under the Creative Commons Attribution International License (CC BY 4.0).

http://creativecommons.org/licenses/by/4.0/

\begin{abstract}
Domestic and international travel study programs have grown in length and popularity since they began in 1923. Regardless of the field of study, the goal of most programs is to enhance student cultural sensitivity. The purpose of this study was to explore the contribution of an undergraduate food-focused domestic travel study program on long-term cultural sensitivity based on the ASKED model. A travel study program focused on transcultural food and cuisine was initiated in 1987 and as of 2017, implemented 22 times. The program length varied between 3 and 5 weeks and was offered in two locations in the United States. A survey developed to explore the long-term impact of the program incorporated the ASKED model of cultural competence. This model includes five domains: cultural awareness, skill, knowledge, encounters, and desire. The survey was validated and found to be reliable. University of Delaware alumni who participated in the travel study program $(\mathrm{n}=461)$ and a comparison group of alumni $(n=402)$ who did not participate in the program were invited to complete the survey. The majority of respondents majored in nutrition and dietetics. Alumni who participated in the travel study program had significantly higher total cultural sensitivity scores and also higher scores on 3 domains, namely cultural skill, knowledge, and desire compared to those that did not. Of the 11 program activities participants were asked to rank as contributors to cultural sensitivity, dining experiences and farm to table tours were rated as the top two, respectively. The study findings provided evidence that a short-term, domestic travel study program enhanced long-term cultural sensitivity. Since domestic programs may be a more cost-effective option and align more closely with employment opportunities in healthcare than international travel programs for college graduates, educators should provide opportunities and encourage dietetic students to participate in these travel programs.
\end{abstract}




\section{Keywords}

Cultural Competence, Cultural Awareness, Cultural Sensitivity, Dietetics, Domestic Travel, Survey, Multicultural, Nutrition

\section{Introduction}

One goal of domestic and international travel study programs is enhancing student awareness of cultures different from their own. America's first study abroad program began in 1923 at the University of Delaware ("Study Abroad Our History", n.d.). Historically, study abroad programs were housed in the language departments of institutions and focused on cultural knowledge and language development (Czerwionka, Artamonova, \& Barbosa, 2015; Martinsen, 2014; Watson, Siska, \& Wolfel, 2013; Watson \& Wolfel, 2013). Since then there has been a shift towards including cultural immersion into a variety of disciplines, transitioning from knowledge based assessments to developing culturally sensitive and competent individuals (Stroud, 2010).

Cultural sensitivity is defined as an individual's ability to recognize that a situation is culturally unique from their own while continuing to function (Martinsen, 2014). Global awareness contributes to cultural sensitivity, and is the cohesion of intercultural awareness, personal growth and development, awareness of global interdependence, and functional knowledge of world geography and language (Chieffo \& Griffiths, 2004). Once an individual has become globally aware, they may transition to become global minded and develop cultural sensitivity (Douglas \& Jones-Rikkers, 2001). An individual that has become culturally sensitive may then transition to the lifelong development of cultural competence. Cultural competence is influenced by several intercultural encounters contributing to a more culturally sensitive individual (Like, Barrett, \& Moon, 2008). Cultural competency is a broader construct consisting of the inter-relationship of cultural knowledge, skills, and attitudes (Watson \& Wolfel, 2013).

College or university non-language based travel study programs have demonstrated positive impact on developing cultural competence of undergraduate students (Stebleton, Soria, \& Cherney, 2013) and on successful preparation for working in a multicultural world (Kitsantas, 2004). Several studies have evaluated the development of cultural competency during undergraduate study abroad programs through pre- and post-travel assessments (Clarke III, Flaherty, Wright, \& Mcmillen, 2009; Kuczmarski\& Cole, 1999; Like, Barrett, \& Moon, 2008; Martinsen, 2014; Stebleton, Soria, \& Cherney, 2013; Watson, Siska, \& Wolfel, 2013; Watson \& Wolfel, 2013). Even a domestic nutrition-related travel study program was effective in stimulating interest, knowledge, and awareness of transcultural food habits based on pre- and post-travel evaluation scores (Kuczmarski \& Cole, 1999). Furthermore, a study assessing cultural competence in students enrolled at the United States Military Academy found significant im- 
provements in their scores on the Intercultural Development Inventory (IDI) upon completing an international travel study program (Watson, Siska, \& Wolfel, 2013; Watson \& Wolfel, 2013). Another study using student interviews before and after a short-term international study abroad program also found that students exhibited newly acquired cultural knowledge (Czerwionka, Artamonova, \& Barbosa, 2015). Overall, short-term, non-language-based domestic and international travel study programs have been shown to improve students' ability to comprehend and accommodate cultural situations that are unique from their norm (Anderson, Lawton, Rexeisen, \& Hubbard, 2006; Chieffo \& Griffiths, 2004; Czerwionka, Artamonova, \& Barbosa, 2015; Martinsen, 2014; Nguyen, 2017).

The importance of cultural sensitivity and competence extends beyond the educational setting and into the professional world. Cultural competency defined at the health care level is the degree of knowledge and skills necessary to effectively care for patients from various ethnic groups (Betancourt, Green, Carrillo, \& Ii, 2018; Like, Barrett, \& Moon, 2008). The ability to recognize and react in culturally unique situations by developing cultural awareness and skills is beneficial for healthcare professionals, whom not only travel frequently themselves, but are often treating patients with a cultural background different from their own (Betancourt, Green, Carrillo, \& Ii, 2018; Gilliland et al., 2016). For example, registered dietitian nutritionists (RDNs) are required to maintain continuing education units (CEUs) from a variety of competencies, including cultural sensitivity, as diet is influenced by cultural background. In fact, some states in the United States have elected to establish cultural competency requirements for practicing health professionals in order to respond to a growing diverse population of patients in the field (Like, Barrett, \& Moon, 2008).

\section{Study Purpose}

Limited research has focused on the long-term impact of domestic travel study programs on cultural sensitivity. However, one study was found that revealed the travel abroad experience enabled participants to develop skills that influenced their future careers, impacting their overall career choice and use of foreign language in their careers (Mohajeri \& Gillespie, 2009). To our knowledge, there has not been a long-term study of the effectiveness of food-focused travel study programs on the development cultural sensitivity of healthcare professionals. The purpose of this study is to explore the benefits an undergraduate food-focused domestic travel study program on contributing to long-term cultural sensitivity based on the ASKED (Awareness, Skill, Knowledge, Encounters, Desire) model.

\section{Methods}

\subsection{Background on the Travel Study Program}

The transcultural food and cuisine course was initiated in 1987. Between 1987 and 2016 the program was offered in Hawaii 18 times and in New Mexico 3 
times. The program included on-campus instruction prior to 3 - 5 weeks of travel. The program focuses on the introduction of the concepts of food and culture and encouragement of self-initiated learning and communication. Overall the travel program was designed to enhance students' intellectual capacity and cultural sensitivity, achieving several knowledge and performance requirements of the Academy of Nutrition and Dietetics, formally the American Dietetic Association (Kuczmarski, 1991; Kuczmarski \& Cole, 1999). The program's instructional objectives, learning activities, assignments, and a sample itinerary have been published elsewhere (Kuczmarski, 1991; Kuczmarski \& Cole, 1999).

\subsection{Background on ASKED Model}

The ASKED model of cultural competence was originally developed in 1998 by Josepha Campinha-Bacote as a means of facing the challenges associated with healthcare provision in an increasingly multicultural setting. The model assumes cultural competence is an ongoing process, consists of five overlapping constructs, is high in intra-ethnic variation, has a direct relationship among healthcare providers and their skill in providing culturally sensitive care, and is necessary to provide culturally effective and responsive services (Campinha-Bacote, 2002). The five constructs of the model are cultural awareness, skills, knowledge, encounters, and desire.

Cultural awareness is the independent exploration of one's existing cultural background (Campinha-Bacote, 2002). Cultural skill is the ability to collect culturally sensitive information about a client that is necessary to provide appropriate care (Campinha-Bacote, 2002). Cultural knowledge refers to the process of developing an educational foundation regarding a variety of cultures (Campinha-Bacote, 2002). Cultural encounter is the process of participating in diverse interactions in a professional and personal manner (Campinha-Bacote, 2002). Cultural desire is the degree to which an individual chooses to participate in the process of increasing cultural awareness, skill, knowledge, and encounters (Campinha-Bacote, 2002). The Inventory for Assessing the Process of Cultural Competence among Healthcare Professionals is one tool developed according to the ASKED model. However, this tool was not used because it does not assess cultural desire, an indicator of long-term and continuous cultural sensitivity.

\subsection{Sample Population}

A total of 863 University of Delaware alumni were invited to participate in this study. All alumni completed a Bachelor's degree and fulfilled a university-wide multicultural class requirement. Since all dietetics majors are required to complete community nutrition, this sample consisted of two groups which meet that requirement: those who only took the on-campus course entitled, "Community Nutrition" ( $\mathrm{n}=461)$ and those who also enrolled in the transcultural foods and cuisine travel study program in addition to the "Community Nutrition" course $(\mathrm{n}=402)$. The transcultural foods and cuisine class was approved by the university to meet the multicultural requirement. The "Community Nutrition" course 
was selected because it included content on culture. Participants were excluded if they attended the University of Delaware as an international student. Class rosters were obtained from an academic advisor for the years of 1987 through 2016. The Office of Alumni Relations provided email and mailing addresses for students included in provided class rosters. The Institutional Review Board of the University of Delaware (FWA \#00004379) reviewed and approved this study.

\subsection{Questionnaire Development}

The survey used in this study was developed using Qualtrics to assess cultural sensitivity based on the ASKED model: cultural awareness, skills, knowledge, encounters, and desire. A variety of Likert-type items were used to assess individual components of the ASKED model (see Supplemental Table 1). Additional sections included questions regarding professional and employment history, and participant demographic information (not shown). Likert-type items were also used to assess the reflective impact of the transcultural travel program coursework and activities (not shown).

\subsection{Questionnaire Pilot Testing}

A series of pilot studies were performed to test understandability of the questions, length of time to complete the survey, and lastly, the validity and reliability of the instrument. In the first round of pilot testing for understandability and timing, the survey was administered to two students in a graduate level research methods class. In a second round of pilot testing, the survey was distributed to twenty-six individuals who completed University of Delaware nutrition-related travel study programs between 2015 and 2018. Thirteen participated in an international travel study program to Switzerland and Italy in June of 2015 directed by a nutrition faculty member. The other thirteen participated in a domestic travel study program to Hawaii in winter of 2018 and have not yet graduated. For the third round of pilot testing, experts from the Institute for Global Studies (IGS) and Center for Teaching and Assessment of Learning (CTAL) reviewed the instrument and provided feedback in accordance with their field. Throughout pilot testing, appropriate modifications were reviewed and applied to the final instrument.

\subsection{Questionnaire Validity Testing}

To assess construct validity, five nutrition faculty members rated each item of the ASKED portion of the survey based on its' relevance and clarity (Ayre \& Scally, 2014). A rating of one on each scale indicated the survey item was not relevant or clear, and a rating of five indicated a survey item was very relevant or clear (Zamanzadeh et al., 2015). Any survey item scored three or below on the scale by a majority of the reviewers was modified as suggested.

\subsection{Implementation of Survey}

Surveys were distributed to participants through e-mail and mailed envelopes to 
those without e-mail addresses. The survey remained active for four weeks, during which time three reminder e-mails requesting participation were sent for those who had not yet responded. An e-mail thanking participants who responded was distributed upon completion of the survey period. Five participants were selected at random to receive a multicultural cookbook in compensation for their time.

\subsection{Questionnaire Reliability Testing}

To assess reliability Cronbach's alpha, the Discrimination Index, change in alpha if item deleted, and intraclass correlation coefficients (ICC) were used. For this study, a Cronbach's alpha value greater than 0.7 would indicate acceptable internal consistency for a component. At the item level removal was considered if a Discrimination Index was below 0.4 or if an item's removal increased alpha (Taib \& Yusoff, 2014). Lastly, the 2-way fixed-effects model ICC was used, with values above 0.7 being considered adequate.

\subsection{Statistical Analysis}

Descriptive characteristics were reported as frequencies. Mean $( \pm S D)$, minimum and maximum ASKED scores were determined individually for each component and for total scores. Median ( \pm interquartile range) ASKED component and total scores were determined for on campus and travel study groups. The Shapiro-Wilk test was used to assess normality; if violated, non-parametric tests were used for between group comparisons. Statistical analysis was completed using IBM Statistical Package for the Social Sciences (SPSS) version 25 (IBM Corp., 2017).

\section{Results}

A flowchart of study participants is provided in Figure 1. Of the 863 students who enrolled in the on-campus course, "Community Nutrition", 402 alumni participated in the travel study program and 335 had contact information filed with the Office of Alumni Relations. Eighty-one of the 84 surveys started were completed. For the 461 students who did not participate in the travel study program, 252 had contact information on file, and 43 of the 55 surveys started were completed.

Internal reliability was high for each component $(\alpha>0.88)$ and every item met the inclusion criteria (Supplemental Table 2). ICC values were $\sim 0.89$ for awareness, knowledge, and desire, suggesting good reliability. ICC values for skills and encounters were 0.933 and 0.908 , respectively, indicating excellent reliability (Table 1).

The descriptive characteristics of each group are provided in Table 2. A majority of respondents from each group were female. For individuals who completed the multicultural requirement on campus, the highest number of respondents was between the ages of $40-44$ years followed by the $45+$ year group. 
Respondents from the travel study group were slightly younger, with 50 out of 81 between 20 - 39 years of age. Fifty-eight of the 124 respondents were currently working as a registered dietitian nutritionist (RDN).

The mean $( \pm S D)$ ASKED component and total scores for the each study group are presented in Table 3. The total cultural skill, knowledge and desire ASKED scores were significantly higher for the travel study group compared to the on-campus group. Due to non-normality seen for each outcome, non-parametric tests were used. Median ( \pm interquartile range) ASKED component and total scores for on-campus and travel study groups are illustrated in Figure 2.

A ranked-order list of 11 trip activities perceived as the most valuable by the respondents who enrolled in an undergraduate travel study program is provided in Table 4. This table provides the ranking by their responses in the "very much" and "quite a bit" categories as well as the sum of these two categories. The top two activities that were thought to enhance their cultural sensitivity the most were the dining experiences and farm to table tours. Sometimes responses associated with activities were equal. For instance, sensory evaluations of foods and participation in traditional cultural ceremonies were equally rated as "very much" in the $6^{\text {th }}$ position of enhancing cultural sensitivity. Visits to Western health-related centers and reflective journals were equally rated as enhancing cultural sensitivity "quite a bit" in the $2^{\text {nd }}$ position, while museums and cultural tours, lectures by professionals, and sensory evaluations of foods scored equally in the $3^{\text {rd }}$ position. Although the ranking changed, all the activities were perceived as valuable to enhance cultural sensitivity by $54 \%$ of the respondents.

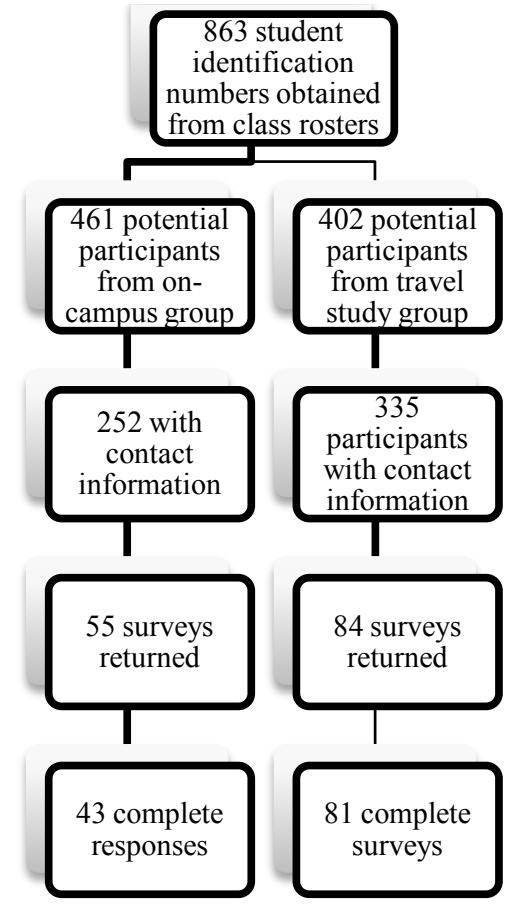

Figure 1. Flowchart of study participants. 


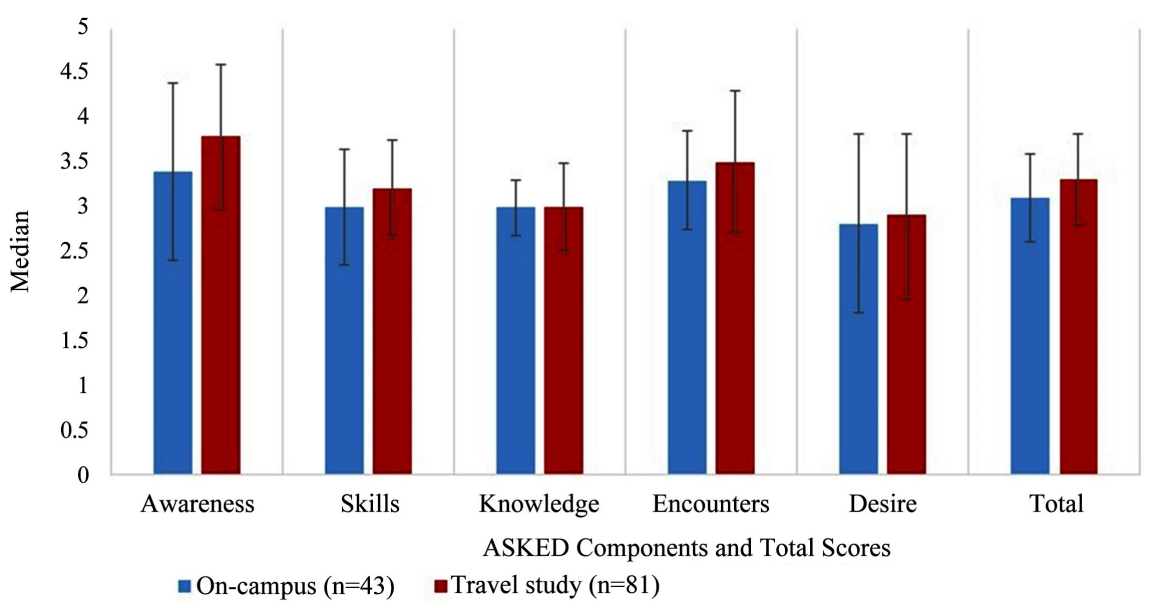

Figure 2. Median ( \pm interquartile range) ASKED component and total scores for on-campus and travel study groups.

Table 1. Intraclass correlation coefficients determined by average-rating, 2-way fixed-effects model.

\begin{tabular}{cccccccc}
\hline \multirow{2}{*}{$\begin{array}{c}\text { ASKED } \\
\text { Component }\end{array}$} & \multirow{2}{*}{$\begin{array}{c}\text { Intraclass } \\
\text { Correlation }\end{array}$} & \multicolumn{2}{c}{ 95\% Confidence Interval } & \multicolumn{3}{c}{ F Test with True Value 0 } \\
\cline { 3 - 8 } & Lower Bound & Upper Bound & Value & $d f 1$ & $d f 2$ & Sig \\
\hline Awareness & 0.891 & 0.857 & 0.918 & 9.134 & 122 & 488 & 0.000 \\
Skills & 0.933 & 0.913 & 0.949 & 14.845 & 114 & 1482 & 0.000 \\
Knowledge & 0.891 & 0.858 & 0.918 & 9.163 & 117 & 819 & 0.000 \\
Encounters & 0.908 & 0.881 & 0.931 & 10.901 & 115 & 1150 & 0.000 \\
Desire & 0.887 & 0.853 & 0.915 & 8.824 & 116 & 1044 & 0.000 \\
\hline
\end{tabular}

Calculations performed using Statistical Package for the Social Sciences, version 25.

Table 2. Descriptive characteristics of on-campus and travel study group participants.

\begin{tabular}{ccc}
\hline Sex & $\begin{array}{c}\text { On-Campus } \\
(\mathrm{n}=43)\end{array}$ & $\begin{array}{c}\text { Travel Study } \\
(\mathrm{n}=81)\end{array}$ \\
Male & 2 & 7 \\
Female & 41 & 74 \\
Age & & 12 \\
20 - 24 years & 3 & 9 \\
$25-29$ years & 6 & 10 \\
$30-34$ years & 3 & 19 \\
$35-39$ years & 3 & 14 \\
40 - 44 years & 17 & 17 \\
45 years or older & 11 & 35 \\
Current Profession & & 0 \\
Registered Dietitian Nutritionist (RDN) & 23 & 16 \\
Registered Dietetic Technician (DTR) & 1 &
\end{tabular}


Table 3. Mean ( \pm SD) ASKED component and total scores for on-campus and travel study groups.

\begin{tabular}{cccc}
\hline ASKED Component & On-Campus $(\mathrm{n}=43)$ & Travel Study $(\mathrm{n}=81)$ & $p$-Value \\
\hline & Mean $( \pm \mathrm{SD})$ & Mean $( \pm \mathrm{SD})$ & \\
Awareness & $3.42 \pm 0.48$ & $3.55 \pm 0.54$ & 0.064 \\
Skills & $3.09 \pm 0.45$ & $3.22 \pm 0.53$ & 0.009 \\
Knowledge & $3.03 \pm 0.43$ & $3.11 \pm 0.58$ & 0.037 \\
Encounters & $3.32 \pm 0.49$ & $3.50 \pm 0.44$ & 0.167 \\
Desire & $2.84 \pm 0.65$ & $2.96 \pm 0.65$ & 0.020 \\
Total & $3.14 \pm 0.40$ & $3.27 \pm 0.44$ & 0.010 \\
\hline
\end{tabular}

Abbreviation: IQ-interquartile range.

Table 4. List of activities ranked in descending order, reported to enhance cultural sensitivity $(\mathrm{n}=81)$.

\begin{tabular}{|c|c|c|}
\hline Very much & Quite a bit & $\begin{array}{l}\text { Sum of very much } \\
\text { and quite a bit* }\end{array}$ \\
\hline Dining experiences & $\begin{array}{l}\text { Participation in traditional } \\
\text { cultural ceremonies }\end{array}$ & Dining experiences (71) \\
\hline Farm to table tours & $\begin{array}{l}\text { Visits to Western } \\
\text { health-related centers } \\
{ }^{\mathrm{s}^{* *}}\end{array}$ & Farm to table tours (66) \\
\hline $\begin{array}{l}\text { Visits to native } \\
\text { health centers }\end{array}$ & Writing a reflective journal $^{a}$ & $\begin{array}{l}\text { Museums and cultural tours specific } \\
\text { to region and population (64) }\end{array}$ \\
\hline $\begin{array}{l}\text { Museums and cultural } \\
\text { tours specific to region } \\
\text { and population }\end{array}$ & $\begin{array}{l}\text { Museums and cultural tours } \\
\text { specific to region and population }\end{array}$ & Visits to native health centers (62) \\
\hline $\begin{array}{l}\text { Engagement with } \\
\text { elder persons }\end{array}$ & $\begin{array}{l}\text { Lectures by professionals engaged } \\
\text { in diet-health outcome activities }\end{array}$ & Engagement with elder persons $s^{a}(61)$ \\
\hline $\begin{array}{l}\text { Sensory evaluations } \\
\text { of foods }{ }^{\mathrm{a}}\end{array}$ & Sensory evaluations of foods ${ }^{\mathrm{b}}$ & $\begin{array}{l}\text { Participation in traditional cultural } \\
\text { ceremonies }^{\mathrm{a}}(61)\end{array}$ \\
\hline $\begin{array}{l}\text { Participation in traditional } \\
\text { cultural ceremonies }\end{array}$ & Engagement with elder persons & Sensory evaluations of foods $(60)$ \\
\hline $\begin{array}{l}\text { Tours of culture-specific } \\
\text { neighborhoods }\end{array}$ & Dining experiences & $\begin{array}{l}\text { Lectures by professionals engaged in } \\
\text { diet-health outcome activities ( } 54 \text { ) }\end{array}$ \\
\hline $\begin{array}{l}\text { Lectures by professionals } \\
\text { engaged in diet-health } \\
\text { outcome activities }\end{array}$ & Visits to native health centers & $\begin{array}{l}\text { Tours of culture-specific } \\
\text { neighborhoods }{ }^{\mathrm{b}}(50)\end{array}$ \\
\hline Writing a reflective journal & Farm to table tours & Writing a reflective journal $\mathrm{l}^{\mathrm{b}}(50)$ \\
\hline $\begin{array}{l}\text { Visits to Western } \\
\text { health-related centers }\end{array}$ & $\begin{array}{l}\text { Tours of culture-specific } \\
\text { neighborhoods }\end{array}$ & $\begin{array}{l}\text { Visits to Western health-related } \\
\text { centers (44) }\end{array}$ \\
\hline
\end{tabular}

${ }^{*}$ Value in parenthesis represents total number of response in very much and quite a bit categories. ${ }^{*}$ Within a column, activities with same superscript received the same number of responses.

\section{Discussion}

The study findings revealed significantly higher cultural skill, knowledge, desire, and overall cultural sensitivity in graduates who participated in a nutri- 
tion-focused travel study program compared to those who participated in a different program or none at all. Therefore, differences in student activities, coursework, and cultural immersion as part of a travel study program seemed to extend beyond undergraduate coursework into the professional world. This finding is noteworthy, as one goal of all travel study programs should be to prepare students for life beyond the classroom. Designing and offering the transcultural food and cuisine course outside of the traditional classroom setting provided a long-lasting impact on students' education.

Continuous follow-up with travel study alumni as they traverse their professional careers is imperative in order to tailor programs to meet the needs of current real-life situations. Another benefit of assessing the post-graduate impact of academic travel study programs is for new program or curricular development. Course evaluation is traditionally done through pre- and post-travel questionnaires. The training received through coursework and experiences in undergraduate education is expected to develop skills and knowledge that can be applied in the professional world. Thus, follow-up post-tests are needed to ensure that skills and knowledge acquired from courses are in fact contributing to career and professional development of alumni. One study followed up with business students one-year post-travel, finding students performed poorly compared to other schools on global dimensions of business (Kamdar \& Lewis, 2015). Therefore, change in the program was warranted.

Culture is dynamic, an inescapable characteristic which contributes to its' complexity. Similarly, travel programs must be dynamic and educators must evaluate the course activities each time they create a program. This program had a variety of activities included in the itinerary, ranging from museum tours to hands-on culinary experiences to writing reflective journals, designed to enhance cultural awareness and sensitivity. Differences in students' perceptions were apparent with respect to which activities enhanced their cultural sensitivity more than others. Dining experiences and farm to table tours were the two highest-ranking activities for enhancing cultural sensitivity, while reflective journaling and visits to Western health-related centers ranked the lowest. Reflective journaling is recognized as a valuable tool for promoting critical thinking skills amongst undergraduates preparing for a career in the health field (Chabon \& Lee-Wilkerson, 2006; Epp, 2008). Reflective journaling is most effective as a learning tool when expectations for content, length, and degree of reflection are shared by educators (Miller, 2017). It is possible that students' desire to learn about a particular topic played a role in these differences. Incorporating a diversity of events within travel study programs is critical to its' effectiveness and success. Programs should be adapted according to the interest of the students attending as well as the resident population of the destination in order to have a long-lasting impact on cultural sensitivity.

The findings of this research document that domestic travel programs can be used to enhance cultural sensitivity of undergraduates. According to US Census data, the nation is a melting pot of a variety of races and ethnicities, with $18.1 \%$ 
identified as Hispanic or Latino, 13.4\% African American, and 5.8\% Asian, as well as $13.2 \%$ of citizens being foreign born. Living in a country with such diversity is both a blessing and a curse, as it allows for cultural immersion in one's own country, but also provides a host of obstacles in dealing with the many differences associated with various cultures. As the demographics of the United States continue to change, racial and ethnic disparities in health care must be addressed (Betancourt, Green, Carrillo, \& Ii, 2018). Specifically, health beliefs and diet are two cultural components that provide grounds for developing cultural sensitivity among health professionals. More research is needed to assess health care professionals' ability to deliver culturally competent healthcare in order to improve the cultural competence of healthcare systems (Ahmed et al., 2018; Anderson, Scrimshaw, Fullilove, Fielding, \& Normand, 2003; Truong, Paradies, \& Priest, 2014). A framework including organizational, structural, and clinical cultural competence interventions that begins early in ones' career is needed to eliminate and prevent health disparities associated with diversity (Betancourt, Green, Carrillo, \& Ii, 2018; Henderson, Horne, Hills, \& Kendall, 2018).

A strength of this study was the use of a survey tool designed to match a previously published model of cultural sensitivity. Additionally, the survey was both reliable and valid. Lastly, it is the first study to provide data on the long-term effects of a food-related travel study program on the development of cultural sensitivity in persons working in health-related positions. However, there are also limitations to be considered. Although the sample size was large enough to support analyses, there was a low response rate and survey results are representative of only participants of a single travel study program at one institution. Therefore, the findings are not generalizable to other programs at the same or different institutions. However, the evidence of long-term impact documented in this study may encourage educators at other institutions to apply the ASKED model survey to their travel study programs.

\section{Conclusion}

An undergraduate food-focused, domestic travel study program, compared to on-campus study improved overall cultural sensitivity as well as cultural skills, knowledge, and desire. Whether traveling domestic or international, students gain the similar benefits, such as but not limited to confidence, independence, networking, and appreciation. The study findings clearly document the long-term effectiveness of domestic travel study in achieving cultural immersion. While research has aimed to provide cultural competence training to practicing health care professionals, more research is needed to 1) evaluate travel study programs aimed at preparing undergraduate health sciences students for a multicultural world, and 2) determine if such programs extend beyond the undergraduate setting into a professional setting.

\section{Acknowledgements}

J.R.E. thanks the many contributors that helped and supported the time and 
work that went into this publication.

\section{Conflicts of Interest}

The authors declare no conflicts of interest regarding the publication of this paper.

\section{References}

(n.d.). Study Abroad Our History.

http://www1.udel.edu/global/studyabroad/information/brief_history.html

Ahmed, S., Siad, F. M., Manalili, K., Lorenzetti, D. L., Barbosa, T., Lantion, V., \& Santana, M. J. (2018). How to Measure Cultural Competence When Evaluating Patient-Centred Care: A Scoping Review. BMJ Open, 8, 1-8. https://doi.org/10.1136/bmjopen-2018-021525

Anderson, L. M., Scrimshaw, S. C., Fullilove, M. T., Fielding, J. E., \& Normand, J. (2003). Culturally Competent Healthcare Systems: A Systematic Review. American Journal of Preventive Medicine, 24, 68-79. https://doi.org/10.1016/S0749-3797(02)00657-8

Anderson, P. H., Lawton, L., Rexeisen, R. J., \& Hubbard, A. C. (2006). Short-Term Study Abroad and Intercultural Sensitivity: A Pilot Study. International Journal of Intercultural Relations, 30, 457-469. https://doi.org/10.1016/j.ijintrel.2005.10.004

Ayre, C., \& Scally, A. J. (2014). Critical Values for Lawshe's Content Validity Ratio: Revisiting the Original Methods of Calculation. Measurement and Evaluation in Counseling and Development, 47, 79-86. https://doi.org/10.1177/0748175613513808

Betancourt, J. R., Green, A. R., Carrillo, J. E., \& Ii, A. (2018). Disparities in Health and Health Care Defining Cultural Competence: A Practical Framework for Addressing Racial/Ethnic Disparities in Health and Health Care. Public Health Reports, 118, 293-302. https://doi.org/10.1016/S0033-3549(04)50253-4

Campinha-Bacote, J. (2002). The Process of Cultural Competence in the Delivery of Healthcare Services: The Journey Continues. Journal of Transcultural Nursing, 13, 181-184. https://doi.org/10.1177/10459602013003003

Chabon, S. S., \& Lee-Wilkerson, D. (2006). Use of Journal Writing in the Assessment of CSD Students' Learning about Diversity. Communication Disorders Quarterly, 27, 146-158. https://doi.org/10.1177/15257401060270030301

Chieffo, L., \& Griffiths, L. (2004). Large-Scale Assessment of Student Attitudes after a Short-Term Study Abroad Program, Frontiers: The Interdisciplinary Journal of Study Abroad, 2004. Frontiers: The Interdisciplinary Journal of Study Abroad, 10, 165-177.

Clarke III, I., Flaherty, T. B., Wright, N. D., \& Mcmillen, R. M. (2009). Student Intercultural Proficiency from Study Abroad Programs. Journal of Marketing Education, 31, 173-181. https://doi.org/10.1177/0273475309335583

Czerwionka, L., Artamonova, T., \& Barbosa, M. (2015). Intercultural Knowledge Development: Evidence from Student Interviews during Short-Term Study Abroad. International Journal of Intercultural Relations, 49, 8099. https://doi.org/10.1016/j.ijintrel.2015.06.012

Douglas, C., \& Jones-Rikkers, C. (2001). Study Abroad Programs and American Student World Mindedness: An Empirical Analysis. Journal of Teaching in International Business, 13, 55-66. https://doi.org/10.1300/J066v13n01_04

Epp, S. (2008). The Value of Reflective Journaling in undergraduate Nursing Education: A Literature Review. International Journal of Nursing Studies, 45, 1379-1388. 
https://doi.org/10.1016/j.ijnurstu.2008.01.006

Gilliland, I., Attridge, R. T., Attridge, R. L., Maize, D. F., \& McNeill, J. (2016). Building Cultural Sensitivity and Interprofessional Collaboration through a Study Abroad Experience. Educational Innovations, 55, 45-48.

Henderson, S., Horne, M., Hills, R., \& Kendall, E. (2018). Cultural Competence in Healthcare in the Community: A Concept Analysis. Health and Social Care in the Community, 26, 590-603. https://doi.org/10.1111/hsc.12556

IBM Corp. (2017). IBM SPSS Statistics for Windows, Version 25.0. Armonk, NY: IBM Corp.

Kamdar, N., \& Lewis, T. (2015). Deriving Long-Term Benefits from Short-Term Study-Abroad Programs. The Journal of Management and Engineering Integration, 7. https://search.proquest.com/docview/1674272205?pq-origsite=summon

Kitsantas, A. (2004). Studying Abroad: The Role of College Students' Goals on the Development of Cross-Cultural Skills and Global Understanding. College Student Journal, $38,441-452$.

Kuczmarski, M. F. (1991). Transcultural Programs: Enhancing the Dietetic Curriculum. Dietetic Currents, 18, 15-18.

Kuczmarski, M. F., \& Cole, R. P. (1999). Transcultural Food Habits Travel Courses: An Interdisciplinary Approach to Teaching Cultural Diversity. Topics in Clinical Nutrition, 15, 59-71. https://doi.org/10.1097/00008486-199912000-00009

Like, R. C., Barrett, T. J., \& Moon, J. (2008). Educating Physicians to Provide Culturally Competent, Patient-Centered Care. Family Medicine, 10-20.

Martinsen, R. A. (2014). Predicting Changes in Cultural Sensitivity among Students of Spanish during Short-Term Study Abroad. Hispania, 94, 121-141.

https://doi.org/10.1016/j.jtumed.2013.12.002

Miller, L. B. (2017). Review of Journaling as a Teaching and Learning Strategy. Teaching and Learning in Nursing, 12, 39-42. https://doi.org/10.1016/j.teln.2016.10.004

Mohajeri Norris, E., \& Gillespie, J. (2009). How Study Abroad Shapes Global Careers. Journal of Studies in International Education, 13, 382-397. https://doi.org/10.1177/1028315308319740

Nguyen, A. (2017). Intercultural Competence in Short-Term Study Abroad. Frontiers: The Interdisciplinary Journal of Study Abroad, 29, 109-127.

Stebleton, M. J., Soria, K. M., \& Cherney, B. (2013). The High Impact of Education Abroad: College Students' Engagement in International Experiences and the Development of Intercultural Competencies. Frontiers: The Interdisciplinary Journal of Study Abroad, 22, 1-24.

Stroud, A. H. (2010). Who Plans (Not) to Study Abroad? An Examination of U.S. Student Intent. Journal of Studies in International Education, 14, 491-507. https://doi.org/10.1177/1028315309357942

Taib, F., \& Yusoff, M. S. B. (2014). Difficulty Index, Discrimination Index, Sensitivity and Specificity of Long Case and Multiple Choice Questions to Predict Medical Students' Examination Performance. Journal of Taibah University Medical Sciences, 9, 110-114.

Truong, M., Paradies, Y., \& Priest, N. (2014). Interventions to Improve Cultural Competency in Healthcare: A Systematic Review of Reviews. BMC Health Services Research, 14, 99. https://doi.org/10.1186/1472-6963-14-99

Watson, J. R., Siska, P., \& Wolfel, R. L. (2013). Assessing Gains in Language Proficiency, Cross-Cultural Competence, and Regional Awareness during Study Abroad: A Preliminary Study. Foreign Language Annals, 46, 62-79. https://doi.org/10.1111/flan.12016 
Watson, J., \& Wolfel, R. (2013). The Intersection of Language and Culture in Study Abroad: Assessment and Analysis of Study Abroad Outcomes. Frontiers: The Interdisciplinary Journal of Study Abroad, 25, 57-72.

https://frontiersjournal.org/wp-content/uploads/2015/09/WATSON-WOLFEL-Frontie rsXXV-TheIntersectionofLanguagenandCultureinStudyAbroad.pdf

Zamanzadeh, V., Ghahramanian, A., Rassouli, M., Abbaszadeh, A., Alavi-Majd, H., \& Nikanfar, A. R. (2015). Design and Implementation Content Validity Study: Development of an Instrument for Measuring Patient-Centered Communication. Journal of Caring Sciences, 4, 165-178. https://doi.org/10.15171/jcs.2015.017

\section{Addendum}

While the original version of the IAPCC did not contain questions regarding cultural desire, in the updated version, the IAPCC-R, questions about cultural desire are included and can be found at this website:

http://transculturalcare.net/iapcc-r/. 
Supplemental Table 1. ASKED model items and possible responses.

\begin{tabular}{cc}
\hline Survey Item & Responses \\
\hline Section 1: Awareness &
\end{tabular}

Thinking back to your study abroad experience, please rate the degree to which you disagree or agree with the following statements regarding your cultural awareness, which refers to an individual's independent exploration of their own cultural background?

- I am able to differentiate between cultures and to be sensitive to the needs of persons different from me.

- I have increased awareness about my own cultural beliefs and practices.

- I reflect about cultural similarities between myself and other individuals.

- I am aware of the importance of being patient with people in the United States who don't speak or understand English as well as I do.

- My personal awareness of my own stereotypes and biases enhances my clinical skills when encountering others.

\section{Section 2: Skills}

Please rate your level of agreement of how skilled you are in dealing with socio-cultural issues in the following areas of client care and/or community programs. Cultural skill is the ability to collect culturally sensitive information about an individual to broaden one's own knowledge of another's culture.

- I have improved my team problem-solving skills.

- I have improved my ability to navigate a location new or foreign to me.

- I have improved my ability to food shop and prepare food in a location new or foreign to me.

- I have enhanced by independent problem-solving skills.

- I have enhanced by respect for a patient's cultural and health beliefs.

- I have identified by own biases and their potential impact on quality of healthcare.

- I have improved my skills greeting clients in a culturally sensitive manner.

- I have improved my skills eliciting information about use of native healers and/or alternative practitioners.

- I have improved my skills prescribing/negotiating a culturally sensitive dietary plan.

- I have improved my skills providing culturally sensitive client education and counseling.

- I have improved my skills providing culturally sensitive clinical services.

- I have improved my skills working with medical interpreters.

- I have improved my skills dealing with cross-cultural adherence or compliance problems (for example, considering periods of fasting or dietary restrictions particular to a certain culture)?

- I have improved my ability to explain cross-cultural misunderstanding or errors.

\section{Section 3: Cultural Knowledge}

Please rate your level of agreement regarding how knowledgeable you are about each of the following subject areas. Cultural knowledge refers to the development of an educational foundation of a variety of cultures.

- I can better describe all of the norms of culturally different people.

- I can describe factors other than biomedical that impact health and underlie health and health-care disparities (i.e. access, historical, political, environmental, and institutional).

- I have deepened my understanding of my own culture.

- I can identify what resources to use to learn about other cultures.

- I can better identify the sociocultural characteristics of diverse racial and ethnic groups.

- I can better identify the health risks of diverse racial and ethnic groups.

- I can better describe the healing traditions of cultures different from my own.

- I can better describe the historical and contemporary impact of racism, bias, prejudice, and discrimination in healthcare experienced by various population groups in the United States.

\section{Section 4: Encounters}

Please rate the degree to which you disagree or agree with the following statements regarding your participation in cultural encounters since graduation. Cultural encounters refer to any interactions with an individual or group of individuals that are culturally different than you.

- I reflected on pursuing a career path in culturally diverse environment.

- My ability to acquire an internship and/or job was enhanced.

- I recognize the existence of health disparities that are amenable to change.

\author{
Strongly disagree (1) \\ Disagree (2) \\ Agree (3) \\ Strongly agree (4)
}

Strongly disagree (1)
Disagree (2)
Agree (3)
Strongly agree (4)

Strongly disagree (1)

Disagree (2)

Agree (3)

Strongly agree (4) 


\section{Continued}

Please rate your comfort level when engaging in the following cultural encounters.

- Providing services to people from different ethnic and racial groups than your own.

- Interpreting different cultural expressions of pain, distress, and suffering.

- Working with healthcare professionals from culturally diverse backgrounds.

- Caring for patients with limited English proficiency.

- Asking clients or caregivers about beliefs that may interfere with the treatment regimen.

- Being attentive to nonverbal cues or the use of culturally specific gestures that might have different meanings in different cultures.

- Encouraging a client to change behaviors or practices related to cultural beliefs that impair one's health.

- If you are not able to communicate directly with a client, speaking to their advocate about his/her illness if this is culturally appropriate.

\section{Section 5: Desire}

Please rate the degree to which you disagree or agree with the following statements regarding your desire to engage in cultural encounters. Desire is the degree to which an individual chooses to increase cultural awareness, knowledge, skill, and encounters. Cultural encounters refer to any interactions with an individual or group of individuals that are culturally different from you.

- It is important to keep ethnic traditions alive.

- I feel that people from other cultures have many valuable things to teach me.

- I look for regional opportunities to interact with people from other cultures.

- I look for national opportunities to interact with people from other cultures.

- My curiosity about other cultures has increased.

Not at all (1)

A little (2)

Quite a bit (3)

Very comfortable (4)

- My desire to try new foods from various cultures has increased.

- My desire to prepare new foods from various cultures has increased.

- I have broadened my perspective of the role ethnic food has on health.

- I have broadened my perspective of the role culture has on health.

Supplemental Table 2. Cronbach's alpha, Discrimination Index, and Cronbach's alpha if item deleted for total and itemized ASKED components.

\begin{tabular}{|c|c|c|c|}
\hline ASKED Component & Cronbach's Alpha ${ }^{a}$ & $\begin{array}{c}\text { Corrected } \\
\text { Discrimination Index }\end{array}$ & $\begin{array}{l}\text { Cronbach's Alpha } \\
\text { if Item Deleted }\end{array}$ \\
\hline Awareness Total & 0.891 & & \\
\hline Item 1 & & 0.715 & 0.871 \\
\hline Item 2 & & 0.787 & 0.854 \\
\hline Item 3 & & 0.747 & 0.864 \\
\hline Item 4 & & 0.644 & 0.886 \\
\hline Item 5 & & 0.780 & 0.856 \\
\hline Skills Total & 0.933 & & \\
\hline Item 1 & & 0.708 & 0.927 \\
\hline Item 2 & & 0.576 & 0.931 \\
\hline Item 3 & & 0.560 & 0.931 \\
\hline Item 4 & & 0.669 & 0.928 \\
\hline Item 5 & & 0.672 & 0.928 \\
\hline Item 6 & & 0.676 & 0.928 \\
\hline Item 7 & & 0.717 & 0.927 \\
\hline Item 8 & & 0.682 & 0.928 \\
\hline Item 9 & & 0.735 & 0.926 \\
\hline
\end{tabular}


J. R. Eosso et al.

\section{Continued}

$\begin{array}{lll}\text { Item } 10 & 0.767 & 0.925 \\ \text { Item } 11 & 0.748 & 0.926 \\ \text { Item } 12 & 0.654 & 0.929 \\ \text { Item } 13 & 0.694 & 0.927 \\ \text { Item } 14 & 0.718 & 0.927\end{array}$

Knowledge Total

0.891

Item 1

$\begin{array}{ll}0.606 & 0.883\end{array}$

Item 2

0.629

0.881

Item 3

0.593

0.884

Item 4

0.738

0.872

Item 5

0.702

0.875

Item 6

0.696

0.874

Item 7

0.665

0.878

Item 8

0.736

0.870

Encounters Total

0.908

Item 1

0.486

0.908

Item 2

0.479

0.908

Item 3

0.471

0.908

Item 4

0.611

0.902

Item 5

0.721

0.896

Item 6

0.734

0.896

Item 7

0.718

0.896

Item 8

0.736

0.895

Item 9

0.693

0.898

Item 10

0.751

0.894

Item 11

0.755

0.894

Desire Total

0.887

Item 1
Item 2
Item 3
Item 4
Item 5
Item 6
Item 7
Item 8
Item 9
Item 10

$\begin{array}{ll}0.484 & 0.885 \\ 0.526 & 0.883 \\ 0.665 & 0.873 \\ 0.665 & 0.875 \\ 0.753 & 0.867 \\ 0.606 & 0.877 \\ 0.628 & 0.876 \\ 0.610 & 0.877 \\ 0.721 & 0.869 \\ 0.642 & 0.874\end{array}$

If $\mathrm{b}<0.30$, that survey item indicates the item may not correlate with the rest of the survey. If $\mathrm{c}<\mathrm{a}$, removing that survey item would reduce the Cronbach's Alpha and internal consistency of the survey. 